\title{
Chromosome Painting
}

National Cancer Institute

\section{Source}

National Cancer Institute. Chromosome Painting. NCI Thesaurus. Code C18154.

Refers to the hybridization of fluorescently labeled, chromosome-specific, composite probe pools to cytological preparations. It allows the visualization of individual chromosomes in metaphase or interphase cells and the identification of both numerical and structural chromosomal aberrations with high sensitivity and specificity. Chromosome painting can be applied to cross-species comparisons as well as to the study of chromosomal rearrangements. The simultaneous hybridization of multiple chromosome painting probes, each tagged with a specific fluorochrome or fluorochrome combination, has resulted in the differential color display of chromosomes, i.e. spectral or color karyotyping. (From Ried et al 1998 Hum Mol Genet 7:1619) 